\title{
Sustainable maternity services in remote and rural Scotland? A qualitative survey of staff views on required skills, competencies and training
}

\author{
J Tucker, V Hundley, A Kiger, H Bryers, J Caldow, J Farmer, F Harris, J Ireland, E van Teijlingen
}

Qual Saf Health Care 2005;14:34-40. doi: 10.1136/qshc.2004.010561

See end of article for
authors' affiliations
........................
Correspondence to:
Dr J Tucker, Dugald Baird
Centre for Research on
Women's Health,
Department of Obstetrics
and Gynaecology,
University of Aberdeen,
Aberdeen Maternity
Hospital, Cornhill Road,
Aberdeen AB25 2ZL, UK;
i.s.tucker@abdn.ac.uk
Accepted for publication
7 September 2004
.........................

\begin{abstract}
Objectives: To explore staff views on their roles, skills and training to deliver high quality and local intrapartum services in remote and rural settings against national recommendations.

Design: Interview and postal survey.

Setting: A stratified representative sample of remote and rural maternity units in Scotland (December 2002 to May 2003).

Participants: Staff proportionally representative of professional groups involved in maternity care. Results: Staff interviews took place at 11 units (response rate 93\%). A subsequent postal survey included the interview sample and staff in a further 11 units (response rate 78\%). Medical specialisation, workforce issues, and proposed regulatory evaluation of competencies linked to throughput raised concerns about the sustainability and safety of services, particularly for "generalists" in rural maternity care teams and for medical cover in small district general hospitals with large rural catchments. Risk assessment and decision making to transfer were seen as central for effective rural practice and these were influenced by rural context. Staff self-reported competence and confidence varied according to procedure, but noted service change appeared to be underway ahead of their preparedness. Self-reported competence in managing obstetric emergencies was surprisingly high, with the caveat that they were not independently assessed in this study. Staff with access to video conference technology reported low actual use although there was enthusiasm about its potential use.

Conclusions: Considerable uncertainties remain around staffing models and training to maintain maternity care team skills and competencies. Further research is required to test how this will impact on safety, appropriateness, and access and acceptability to rural communities.
\end{abstract}

of women to higher levels for specialist acute care. They suggest extended roles for midwives and neonatal nurses to sustain local access for low risk women, and define the procedures in which staff are required to be competent (box 1)..$^{311}$

The objectives of this study were to explore the views of staff in remote and rural Scotland about their current and future roles, whether they had the competencies set out in national recommendations ${ }^{23}$ to deliver local high quality intrapartum services, and their views on training and maintaining skills. We used a broad definition of competence that included knowledge, understanding, judgement, interpersonal and clinical skills to ensure "fitness to practise" and meet the challenge of further centralised and reconfigured acute perinatal services.

\section{METHODS}

The study was undertaken in three phases in remote and rural maternity units in Scotland from December 2002 to May 2003.

\section{Phase 1: Sampling maternity units}

Routine data were used to identify units with low annual deliveries $(<300)$ as a proxy for rural and remote settings, and included all eight small district general hospitals with large rural catchments (annual deliveries 1200). ${ }^{13} \mathrm{~A}$ structured telephone interview with midwife managers also sought contemporary annual deliveries and models of service to check eligibility. Size of unit, as annual deliveries per annum, were divided into four categories as <50, 50-149, 150-299, 300-1200. Eligible units were stratified using the

Recent maternity care policy and standards documents in the UK emphasise risk assessment for appropriate allocation 


\section{Box 1 Key policy and standards}

- Joint Working Group of the Society of Rural Physicians of Canada (1998). ${ }^{8}$ Rural obstetrics: joint position on rural maternity care setting standards for maternity care.

- The National Framework for Maternity Services in Scotland (SEHD 2001)." Describes seven levels of intrapartum care, recognises existing diversity in organisation and staffing and the scant information about rural maternity care.

- RARARI (Remote and Rural Areas Resource Initiatives-Solutions Group (2002).9 Solutions for the provision of health care in remote and rural areas of Scotland in the 21 st century recommends training and multiprofessional workforce recommendations.

- Expert Group on Acute Maternity Services (EGAMS SEHD 2002) ${ }^{2}$

- charged with implementing the framework policy;"

- standards emphasise risk assessment for allocation to appropriate levels of care;

- EGAMS and the Maternity and Neonatal Workforce Group in England and Wales ${ }^{3}$

- suggest extended roles for midwives and neonatal nurses to sustain local access for low risk women;

- core competencies for staff providing care for low risk women in any setting are defined, with two additional competencies of antenatal ultrasound scanning and Ventouse delivery required by remote and rural practitioners. $^{2}$

EGAMS recommended hierarchy of unit types with increasing provision of acute obstetric and neonatal care (unit levels $1 \mathrm{~A}$ to $11 \mathrm{C}$ ) and unit size (deliveries per annum), table $1 .^{211}$ Purposive sampling included at least one unit from each represented unit type, ensured geographical spread, and included island and mainland settings.
Phase 2: Staff interviews

Five to seven staff in each participating maternity unit were invited to be interviewed, ensuring proportional professional representation of each workforce. A semi-structured interview schedule to explore staff experiences and perceptions was designed, informed by literature review and experience within the project team and Advisory Group. ${ }^{14}$ The schedule was piloted with two midwives, a GP, and a paramedic. Minor changes included exploring skills and competencies separately and adding prompts about staff recruitment methods used in the interviewee's unit. Four researchers conducted audiotaped interviews after obtaining full informed consent. Checks on consistency between interviewers included a training day and review of their first interview recording. Tapes were transcribed verbatim. Analysis was based on the constant comparative method, with coding and identification of themes/categories and their properties from both field notes and subsequent full thematic analysis of transcripts. ${ }^{15}{ }^{16}$ Each transcript was coded by at least two researchers in the team.

\section{Phase 3: Postal questionnaire for staff}

A postal survey tested the validity and reliability of interview findings both with the interview sample and a matched sample of staff from a second tier of stratified units (table 1 ). ${ }^{17}$ The questionnaire, containing demographic questions and items on the interview themes, was developed, piloted and mailed with one reminder. The questions were closed and included Likert scales to rate agreement with opinions elicited from interviews. One open-ended question invited additional comments. Data were collated and descriptive analysis used SPSS for Windows. ${ }^{18}$ Thematic analysis of replies to the open question was undertaken as described above. ${ }^{15}$

\section{RESULTS}

Sample

Of 28 eligible maternity units (accounting for 14\% (7377/ 51642 ) of total annual deliveries in Scotland in 2001), ${ }^{13} 11$ were selected for phase 2 (interview sample, $\mathrm{n}=75$ ) and a further 11 for phase 3 (additional staff questionnaire sample, $\mathrm{n}=85)$. All invited units agreed to participate. Staff response rates for the interviews and questionnaires were 93\% (70/75) and $78 \%$ (124/160), respectively, and midwives proportionally represented the largest professional group (table 2).

Table 1 Selected sample of eligible remote and rural units stratified by maternity care model ${ }^{2}$ and size of unit

\begin{tabular}{|c|c|c|c|c|}
\hline Maternity care model $^{2}$ & $\begin{array}{l}\text { Stratified by size } \\
\text { of unit (deliveries } \\
\text { per annum) }\end{array}$ & $\begin{array}{l}\text { No of eligible units } \\
\text { from census }\end{array}$ & $\begin{array}{l}\text { No of units selected } \\
\text { for interviews } \\
\text { (phase 2) }\end{array}$ & $\begin{array}{l}\text { No of additional units } \\
\text { selected for questionnaires } \\
\text { (phase 3) }\end{array}$ \\
\hline 1A: Planned home delivery & $<50$ & 2 & 1 & 1 \\
\hline $\begin{array}{l}\text { 1B: Stand alone community } \\
\text { maternity unit }\end{array}$ & $\begin{array}{l}<50 \\
50-149\end{array}$ & $\begin{array}{l}8 \\
5\end{array}$ & $\begin{array}{l}2 \\
1\end{array}$ & $\begin{array}{l}2 \\
2\end{array}$ \\
\hline $\begin{array}{l}\text { 1C: Community maternity unit adjacent to } \\
\text { non-obstetric hospital }\end{array}$ & $\begin{array}{l}<50 \\
50-149\end{array}$ & $\begin{array}{l}2 \\
3\end{array}$ & $\begin{array}{l}1 \\
2\end{array}$ & $\begin{array}{l}1 \\
1\end{array}$ \\
\hline $\begin{array}{l}\text { 1D: Community maternity unit adjacent to } \\
\text { maternity unit* }\end{array}$ & & 0 & - & - \\
\hline $\begin{array}{l}\| A \text { : Consultant-led maternity unit with no } \\
\text { neonatal facility }\end{array}$ & $\begin{array}{l}150-299 \\
300-1200\end{array}$ & $\begin{array}{l}1 \\
2\end{array}$ & $\begin{array}{l}1 \\
1\end{array}$ & $\begin{array}{l}0 \\
1\end{array}$ \\
\hline $\begin{array}{l}\text { IIB: Consultant-led maternity unit with } \\
\text { neonatal facility }\end{array}$ & $\begin{array}{l}150-299 \\
300-1200\end{array}$ & $\begin{array}{l}1 \\
1\end{array}$ & $\begin{array}{l}1 \\
0\end{array}$ & $\begin{array}{l}0 \\
1\end{array}$ \\
\hline $\begin{array}{l}\text { IIC: Full consultant-led maternity unit with } \\
\text { neonatal facility }\end{array}$ & $300-1200$ & 3 & 1 & 2 \\
\hline Total & & 28 & 11 & 11 \\
\hline
\end{tabular}




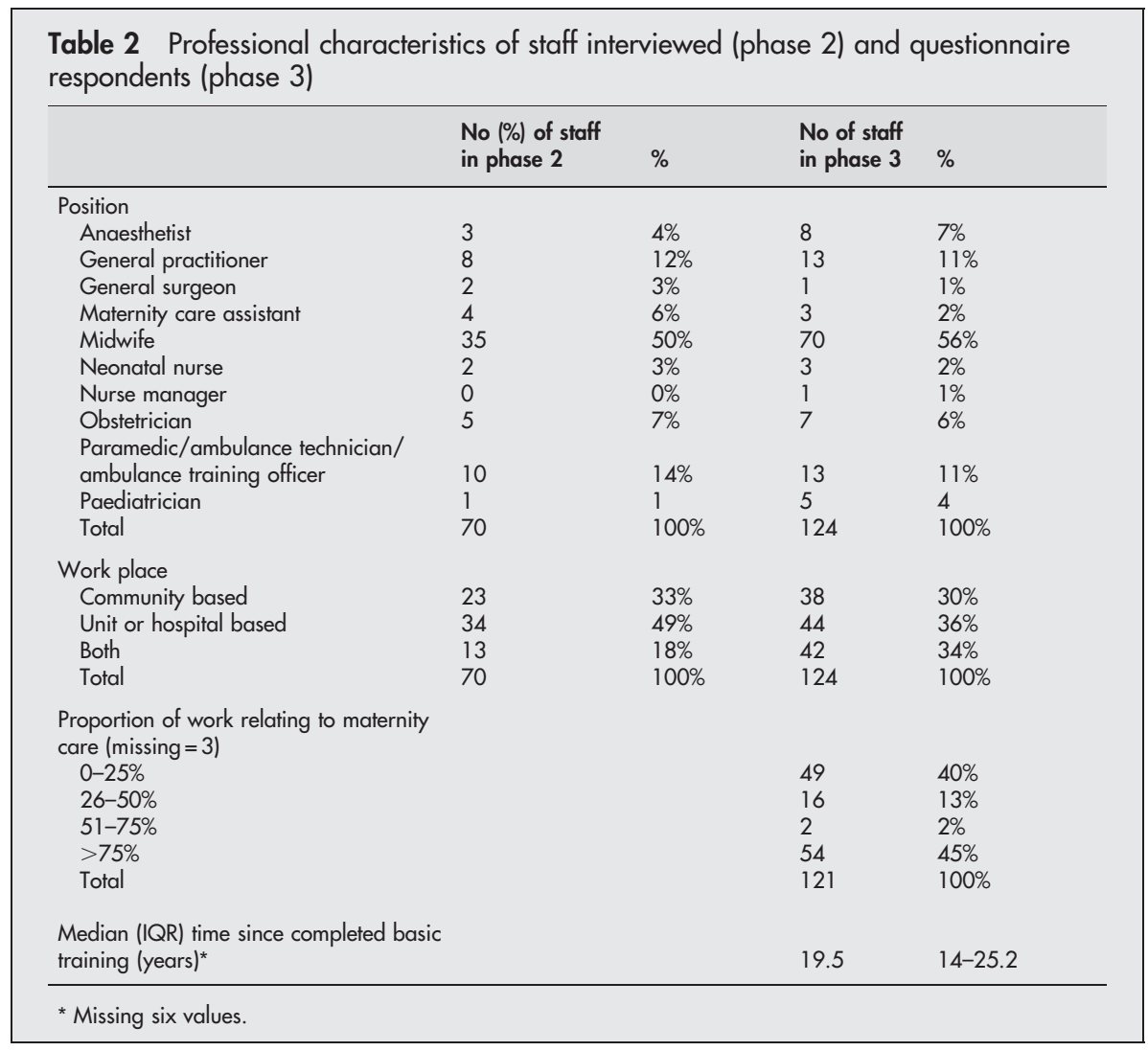

\section{Themes}

Themes generated by analysis of the interviews were:

- the roles and skills of the rural maternity care team;

- the influence of the remote and rural context on delivering maternity care;

- competence and confidence in clinical practice; and

- issues around skills maintenance and training.

Findings in each theme are outlined below. Relevant questionnaire item results are included to indicate the extent of agreement in the wider rural maternity care staff.

\section{Maternity care team}

Interview data suggested that many rural professionals, including midwives in dual and triple duty posts, had to maintain a broad range of skills as generalists. For paediatricians, surgeons and anaesthetists, maternity and neonatal care was only one part of their role in small district general hospitals. Medical cover appeared increasingly unsustainable to some clinicians because of contemporary training to sub-specialty level, UK Government Junior Doctor Working Time Directives, ${ }^{19}$ and requirements of specific numbers of cases to maintain competence. Thus, one general surgeon said:

"The way surgical and medical training has gone is that subspecialisation is the order of the day. (...) [An issue] for the college is the fact that these people are just totally untrained for working in our areas. So as we resign, retire, move out, die off, die out, we're not being replaced, because there's no-one to replace us." (Interview 12, surgeon)

Similarly, general practitioners noted their requirement to maintain skills across many areas. Some noted that, because they no longer obtained much obstetric experience during pre-registration nor maintained skills for intrapartum care and neonatal resuscitation, any intrapartum care in commu- nity settings was increasingly undertaken by midwives. Paramedics and ambulance staff thought that others in the maternity care team were unaware of their basic training skills. They suggested that they needed more practical experience in maternity units to deal with a possible increase in roadside deliveries in further centralised services. The roles allocated to maternity care assistants varied widely. Their skills were gained on the job and ranged from supervision of wards for midwives on-call, to giving advice on breastfeeding.

"I think when women have a baby it is a time when they do need people to sit and listen to them and help them, especially when it comes to breastfeeding and things like that." (Interview 47, maternity care assistant)

Questionnaire responses confirmed variation in the proportions of staff groups' time spent delivering maternity care: $40 \%(49 / 121)$ with less than a quarter and $45 \%$ (54/121, all midwives or neonatal nurses) with more than three quarters of their work related to maternity care (table 2). Findings from both interviews and questionnaires showed positive staff attitudes about their good teamwork and continuity of care, and that current maternity team structures were local solutions to local conditions.

\section{Maternity care and remote and rural context}

Findings from interviews indicated that personnel in small rural units felt they had to be thoroughly trained in emergency obstetric procedures, with final responsibility falling according to the professional staffing model in place. As one midwife noted:

"Well, we are aware that the buck stops here in a sense, and there's nobody else to call on" (Interview 7, midwife)

The interview data highlighted the personal impact of an adverse outcome in a small community. Additional comments noted concerns about maintaining safety and quality of local care given planned changes in response to national policy and recommendations (box 1). In response to the open questionnaire item that invited further comments on aspects 
of their work or unit, respondents across the professional groups noted concerns about service changes that they perceived undermined sustainability, safety, and quality of patient care locally. Thus:

"Having our local maternity hospital closed after $5 \mathrm{pm}$, we have to travel approximately 15 miles to the nearest maternity hospital ... I feel this puts extra pressure on ambulance staff to get to the hospital in time. Also there is greater risk of accidents travelling at higher speeds. We do not, now, have the backing of midwives at night ..." (Questionnaire open comment, paramedic 0082)

"... our unit is currently going midwifery-led despite levels of concern regarding our skilled ambulance service cover and changes, threatened closure of our nearest consultant unit, etc. I feel our concerns are not really being heard or acknowledged by management. I think there is definitely a disaster waiting to happen ..." (Questionnaire open comment, midwife 0084)

"Huge concerns arise over the increasing number of prims [primigravidae] seeking delivery in our small DGH as a result of rationalisation of services to the centre." (Questionnaire open comment, anaesthetist 0100)

"... [my unit is] under threat. I have worked in seven different maternity units [and] this one gives far superior levels of care compared with the other seven (bigger units). Closing this [unit] will lead to a significant decrease in quality of care for women here, and also for women in the larger unit they will be moved to ..." (Questionnaire open comment, anaesthetist 0134)

"... the system was working pretty well, but the [unit] is now under threat, mainly because it is becoming increasingly difficult to recruit GPS who will do intrapartum obstetrics ..." (Questionnaire open comment, general practitioner 0026)

Not surprisingly, staff also emphasised the distance and geographical barriers to specialist acute services. As one GP said:

"It's the time, it's the distance, it's the geography, it's the weather ... in the wintertime even helicopters don't fly" (Interview 21, general practitioner)

There were accounts that staff in referral units did not always understand the effect of location on risk assessment and decisions to transfer by some remote and rural professionals. From the questionnaire, nearly half the respondents $(47.5 \%, 58 / 122)$ agreed that staff in referral units had little understanding of the constraints around transporting women, but 37\% (45/122) disagreed and 15.5\% (19/122) were uncertain.

\section{Competence, confidence, and decision making}

In maintaining competence after registration staff rely on portfolios, subjective self-assessment, and reflective practice in continuing professional development (CPD), with facilitating supervisors for midwives and clinicians training in specialty. For some staff interviewed it was not just a matter of competence; they needed to feel confident.

"My greatest concerns don't really lie around competency. I think people can, once having obtained competency that they feel that they can function upon ... they can run with that as long as they can maintain those competencies, but I think there is a clear issue of confidence. Midwives have lost their confidence (in my opinion) to manage out-with a medical model ..." (Interview 37, midwife)

Confidence was seen to be supported by good working relationships in the maternity care team and attained through experience and structured training, particularly when throughput was low. Ventouse delivery, perineal suturing, and cannulation were mentioned in interviews as areas requiring development of competence and confidence.

The questionnaire then asked staff whether they were competent in each of the 15 core clinical procedures required by EGAMS ${ }^{2}$ and their confidence level for each (table 3). The fndings were consistent with interview findings. Unsurprisingly, few rural staff $(<20 \%)$ had the required new competencies in ultrasound scanning and Ventouse delivery (box 1) and, of those few who felt competent to undertake a Ventouse delivery (20/109, 19\%), only 14 felt confident. Around half of respondents reported that they were competent in four core competencies (newborn examinations, breech delivery, prescribing drugs and perineal repair), with notably fewer feeling confident about breech delivery and perineal repair. Most respondents ( $80 \%$ or more) said they were competent and mainly confident in the management of intravenous fluid replacement, antepartum haemorrhage, normal delivery, cord prolapse, postpartum haemorrhage, and basic obstetric life support, although fewer were confident about cord prolapse. Despite in-house training with mannequins or fire drills for obstetric emergencies, interviewees most valued supervised practice on real patients. Nearly two thirds of questionnaire respondents (65\%, 79/122) agreed that competence could not be maintained using models alone.

In interviews staff did not simply list procedures and competencies. They identified broader skills such as communication and risk assessment. Risk assessment was one key skill and decision to transfer was noted as not only a criteria based clinical decision but considered the individual case and remote context, as described above.

One GP said:

"one of the keys to successful practice is to try and identify problems or anticipate problems before they happen." (Interview 2, general practitioner)

Some respondents spoke of experience and intuition in feeling that something was "wrong." Thus:

"It was a matter of taking a step back and observing a woman closely and really 'feeling' the situation, in that way working out what it was that worried you about someone" (Interview 42, midwife).

Around three quarters of questionnaire respondents said they had formal referral protocols for women $(74 \%, 89 / 121)$ and for infants $(64 \%, 78 / 121)$. A minority did not know whether such protocols existed $(8 \%, 10 / 121$ (protocols for women) and 15\%, 19/121 (protocols for infants)). EGAMS recommends that there should be a network for advice and management for increasingly acute levels of care. ${ }^{2}$ Although $70 \%(85 / 122)$ of respondents agreed that in their areas such a network existed for advice and 75\% (92/123) for management, a substantial proportion were uncertain (21\%, (25/122) for advice and 19\% (23/123) for management).

\section{Maintaining skills and training issues}

From the interviews, placements in tertiary units were noted as one way to maintain skills, although some staff believed that district general hospitals were better for "hands on" experience. Some believed that doing as many procedures as possible in a placement was all that was required, whereas others suggested that it was not the number of cases but reflective practice that was important. Similarly, opinions varied widely in questionnaire data about becoming "deskilled" with few deliveries, and most respondents omitted the section that asked them to specify the numbers of cases annually they thought were needed to maintain each competency. Some noted they were unable or unwilling to do so.

"I find number of cases difficult to answer. It would depend on your previous experience and additional training." (Questionnaire open comment, midwife 0081)

Those who did respond gave widely differing numbers, and only $42 \%(51 / 121)$ agreed with the statement in the questionnaire: "It's like riding a bike-once you have delivered babies you don't forget how."

Noted obstacles to training mentioned in interviews included lack of funding, longer absences because of travel 


\begin{tabular}{|c|c|c|c|c|}
\hline & \multicolumn{2}{|c|}{$\begin{array}{l}\text { Respondents competent } \\
\text { to do this* } \\
\text { (total } n=124 \text { ) }\end{array}$} & \multicolumn{2}{|c|}{$\begin{array}{l}\text { Of those competent, those } \\
\text { "confident" or "very } \\
\text { confident" to do this" }\end{array}$} \\
\hline & $\mathrm{N}$ & $\%$ & $\mathrm{~N}$ & $\%$ \\
\hline $\begin{array}{l}\text { Ultrasonic scanning } \\
\text { [missing 12] }(N A=0)\end{array}$ & $20 / 112$ & 18 & $20 / 20$ & 100 \\
\hline $\begin{array}{l}\text { Undertaking a Ventouse liff-out delivery } \\
\text { [missing 15] }(\mathrm{NA}=3)\end{array}$ & $20 / 109$ & 19 & $14 / 20$ & 70 \\
\hline $\begin{array}{l}\text { Initial and discharge examination of the } \\
\text { newborn [missing 7] (NA=1) }\end{array}$ & $55 / 117$ & 47 & $52 / 55$ & 95 \\
\hline $\begin{array}{l}\text { Management of breech delivery [missing 12] } \\
(\mathrm{NA}=2)\end{array}$ & $59 / 112$ & 53 & $40 / 59$ & 68 \\
\hline $\begin{array}{l}\text { Prescription of drugs [missing 8] (NA=2) } \\
\text { Repair of perineal trauma [missing 12] } \\
(\mathrm{NA}=2)\end{array}$ & $\begin{array}{l}64 / 116 \\
63 / 112\end{array}$ & $\begin{array}{l}55 \\
56\end{array}$ & $\begin{array}{l}60 / 64 \\
51 / 63\end{array}$ & $\begin{array}{l}94 \\
81\end{array}$ \\
\hline $\begin{array}{l}\text { Intravenous (IV) cannulation [missing 5] } \\
(\mathrm{NA}=3)\end{array}$ & $76 / 119$ & 64 & $71 / 76$ & 93 \\
\hline $\begin{array}{l}\text { Management of shoulder dystocia [missing 13] } \\
(\mathrm{NA}=2 \text { ) }\end{array}$ & $82 / 111$ & 74 & $70 / 82$ & 85 \\
\hline $\begin{array}{l}\text { Managing IV fluid replacement [missing 6] } \\
\text { (NA=7) }\end{array}$ & $90 / 118$ & 76 & $80 / 90$ & 89 \\
\hline $\begin{array}{l}\text { Management of cord prolapse [missing 12] } \\
\text { (NA=3) }\end{array}$ & $98 / 112$ & 88 & $76 / 98$ & 78 \\
\hline $\begin{array}{l}\text { Management of normal delivery [missing 13] } \\
(\mathrm{NA}=1)\end{array}$ & $99 / 111$ & 89 & $91 / 99$ & 92 \\
\hline $\begin{array}{l}\text { Management of antepartum haemorrhage } \\
\text { [missing 11] (NA=4, missing =2) }\end{array}$ & $102 / 113$ & 90 & $87 / 102$ & 85 \\
\hline $\begin{array}{l}\text { Management of postpartum haemorrhage } \\
\text { [missing 13] }(N A=1)\end{array}$ & $101 / 111$ & 91 & $90 / 101$ & 89 \\
\hline Neonatal resuscitation [missing 6] $(N A=1)$ & $108 / 118$ & 92 & $93 / 108$ & 86 \\
\hline $\begin{array}{l}\text { Basic obstetric life support [missing 11] } \\
(\mathrm{NA}=1)\end{array}$ & $107 / 113$ & 95 & $100 / 107$ & 93 \\
\hline
\end{tabular}

times to venues, and lack of staff cover. There was support and enthusiasm to use video-conferencing for education, particularly among those who had never used it. The questionnaire data showed $48 \%$ of respondents (57/120) had access to video-conferencing. Of these, around half knew how to use it $(56 \%, 32 / 57)$. There was general support for multidisciplinary training although some preferred profession specific training because "it's difficult to pitch the education at the right level for the whole audience." (Interview 2, general practitioner)

\section{DISCUSSION}

We found staff concerned about the sustainability of intrapartum care in remote units and beliefs that safety and quality of local service were threatened due to loss of medical cover, perhaps ahead of staff preparedness. Much of the UK evidence about the safety of midwife managed intrapartum care for low risk women arises from urban studies in "along-side" midwife units in tertiary settings and may not be generalisable to "stand-alone" midwifery units in remote settings. ${ }^{10}$ Similarly, whereas post-registration midwifery skills have been explored in urban tertiary settings, we could find no reported evidence of training in rural maternity care towards sustaining services or effect on quality of care. $^{2021}$

The professional composition of rural maternity care teams varied and current maternity team structures were local solutions to local conditions. Overall, levels of staff selfreported competence and confidence varied widely in the required core procedures. The surprisingly high competence levels in obstetric emergencies-for example, 91\% reported competence to manage postpartum haemorrhage-are selfassessed and may not reliably reflect true workforce levels. Efforts are required to identify objective assessment of competence. We found staff needed to feel confident as well as competent, but were reluctant to define numbers of procedures required to maintain competence. Such requirements are often expert defined and flow from the premise that "practice makes perfect" ${ }^{\prime 22}$ Emerging literature in health technology emphasises learning and performance theories, and individual differences in learning curves and skills decay in relatively simple psychomotor skills and procedures. ${ }^{23}$ However, there is little evidence around what works in complex skills maintenance programmes and, crucially, what this may mean for outcomes for women and quality and sustainability of services.

\section{Key messages}

- International rural policy recommends multidisciplinary staff training to sustain local and high quality intrapartum care.

- There were diverse models in rural maternity care teams and levels of self-reported competence and confidence in the required competences varied.

- Rural staff emphasised context-specific risk assessment and decision making to transfer as a key skill.

- Staff noted barriers to training and voiced concerns about the effects of increasing medical specialism and proposed regulatory evaluation of competencies linked to throughput.

- Further research in rural settings is required to test the impact of new staffing models and training, not only on staff practice but also on quality and outcomes. 
Professionals did not simply list competence in clinical procedures in interview but discussed skills in risk assessment and decision making in transfers to ensure women received appropriate levels of care. ${ }^{2}$ Some observed that staff in a referral unit did not always agree with the appropriateness of their decisions to transfer because referral unit staff had a poor understanding of how distance and geography affect decisions to transfer. This finding could be interpreted as one explanatory factor of the more cautious approach to risk in rural maternity care that has been reported previously. ${ }^{24}{ }^{25}$ The finding of using intuition in risk assessment is of interest and an example of a continuing tension between the paradigms of evidence based guidelines to identify "at risk" women versus clinical practice as an art.

The barriers and problems to training rural staff were highlighted. Tele-health technologies are often suggested to offset reduced access in rural areas. In relation to training, we found low actual use of video-conferencing facilities where available, yet enthusiasm for its use in education as a hypothetical option. There is, as yet, little evidence about cost effectiveness of tele-health, although video-conferencing has been used for neonatal resuscitation education in areas with few instructors. ${ }^{26}$

The main strengths of this study are that it includes 22 of 28 eligible units, representing all types of units and professional groups involved in remote and rural maternity care in Scotland. It explores staff views on competence and training needs against recommendations and tests interview findings in a wider survey. Limitations of the study include the fact that it focuses on staff views of services and, as staff competence was self-reported, findings may be unreliable. This study neither observed staff practice nor explored how staff training and service redesign might impact on quality of care for women and their families. Because of inherent limitations of small staffing establishments in rural units, we were unable to explore differences within or between unit types or professional groups.

However, these findings may better inform policy makers and planners by providing descriptive information and understanding of the service and workforce context in which policies will be implemented. ${ }^{27}$ There remain considerable uncertainties-not only about how best to undertake rural staff training, objective assessment of competence, and effective training interventions, but crucially how workforce and practice changes will impact on sustainable, safe, and local services for women in rural and remote settings. Further research is needed about staffing and quality issues of safety, clinical appropriateness and transfers, costs, client preferences and acceptability in rural maternity services.

\section{ACKNOWLEDGEMENTS}

The authors acknowledge the advice, support, and assistance of both the Steering Group and the Professional Advisory Group. Special thanks go to the staff at the maternity units across Scotland who gave their valuable time. Participating units included Forfar, Mid Argyll, Dunoon, Uist, Arran, Portree, Montrose, Peterhead, Banff, Cresswell, Borders, Inverclyde, Elgin, Vale of Leven, Perth, Caithness, Western Isles, Orkney, Stranraer, Lerwick, Fort William and Oban.

\footnotetext{
Authors' affiliations

J Tucker, Dugald Baird Centre, Department of Obstetrics and Gynaecology, University of Aberdeen AB25 2ZL, UK

V Hundley, A Kiger, F Harris, J Ireland, Centre for Advanced Studies in Nursing, University of Aberdeen, Aberdeen AB25 2AY, UK

H Bryers, Raigmore Hospital, NHS Highland, Inverness IV2 3UJ, UK

J Caldow, Department of General Practice and Primary Care, University of Aberdeen, Aberdeen AB25 2AY, UK

J Farmer, University of Aberdeen Management School, Old Aberdeen AB24 3QY, UK
}

E van Teijlingen, Department of Public Health, University of Aberdeen, Aberdeen AB25 2ZD, UK

This study was supported by NHS Education for Scotland (grant number CP123).

JT was responsible for study design, sampling and analysis and is a coauthor; $\mathrm{AK}$ was responsible for study design, qualitative analysis and is a co-author; $\mathrm{VH}$ was responsible for study design, questionnaire design, quantitative analysis and is a co-author; JF was responsible for interview design, qualitative analysis and is a co-author; $\mathrm{JC}$ was project manager, interviewer and data collection; $\mathrm{FH}$ interviewer and qualitative analysis; EvT Jl and HB literature review. Guarantors: JT, VH and AK. The views expressed are those of the authors.

Steering Group NHS Education for Scotland: Mrs Sue Hickie (Professional Officer, NHS Education for Scotland), Dr Sue Kinn (Programme Leader, Nursing Research Initiative for Scotland), Dr Margaret McGuire (Midwifery Development Officer, SEHD/Royal College of Midwives/UK Board for Scotland); Dr Brian McKinstry (Director of Research, NHS Education for Scotland); Dr Tricia MurphyBlack (Professor of Midwifery, University of Stirling); Mrs Monica Thompson (Professional Officer (Midwifery), NHS Education for Scotland); Dr Sally Wyke, Director, Scottish School of Primary Care, NHS Education for Scotland.

Professional Advisory Group: Joanne Thorpe and Jaki Lambert, Clinical Midwifery Specialist, Lochgilphead, Argyll; Sarah MacLeod, Midwifery manager, Belford Hospital, Fort William; A Gordon Baird, General Practitioner, Dumfries \& Galloway; Liz Coutts, General Practitioner, Lerwick, Shetland; Beverly Beasant, NES researcher on Telemedicine in Training, University of Dundee; Norman Smith, Consultant, Director of Clinical Obstetric Services, Aberdeen Maternity Hospital; Bill Haining. Scottish Ambulance Services, The Scottish Ambulance College, Barony Castle; Rita Finlayson, Advanced Neonatal Nurse Practitioner, Raigmore Hospital, Inverness; Mike Munro, consultant neonatologist, Aberdeen Maternity Hospital; David Godden, Professor of Remote and Rural Health Care Issues, Director, Highlands and Islands Health Research Institute, University of Aberdeen, Inverness; Helen MacLean, Western Isles Health Council, Benbecula Office; Anne MacKay, Senior Lecturer, School of Nursing \& Midwifery, Robert Gordon University, Aberdeen.

\section{REFERENCES}

1 Advisory Group to Review the Scottish Medical Workforce. Future practice: proposals of an advisory group to review the Scottish medical workforce, The Temple Report. Edinburgh, Scottish Executive Health Department, 2002 (www.scotland.gov.uk/library5/health/fpmr-00.asp).

2 Report of the Expert Group on Acute Maternity Services (EGAMS) Implementing a framework for maternity services in Scotland. Edinburgh Scottish Executive Health Department, 2002 (http://www.scotland.gov.uk/ library5/health/egas.pdf)

3 Department of Health. Report to the Department of Health Children's Taskforce from the Maternity and Neonatal Working Group. London, Department of Health, 2003 (http://www.doh.gov.uk/maternitywg/reportjan03.pdf).

4 Farmer J, Iversen L, Baird G. Rural deprivation: reflecting reality. $\mathrm{Br} J \mathrm{Gen}$ Pract 2001;51:486-91.

5 Williams N, Shucksmith M, Edmond H, et al. Scottish rural life update: a revised socio-economic profile of rural Scotland. Edinburgh: Scottish Office Central Research Unit/TSO, 1998.

6 Rourke J. In search of a definition of "rural". Can J Rural Med 1997;2:113-5.

7 Gryzybowski SC. Problems of providing limited obstetrical services to small, isolated, rural populations. Can Family Physician 1998;44:230-3.

8 Joint Working Group of the Society of Rural Physicians of Canada (SRPC) The College of Family Physicians of Canada (CFPC) Committee on Maternity Care, the Society of Obstetricians, Gynaecologists of Canada (SOGC). Rural obstetrics: joint position on rural maternity care. Can J Rural Med 1998:3:75-82.

9 Remote, Rural Areas Resource Initiative Solutions Group (RARARI). Solutions for the provision of health care in remote and rural areas of Scotland in the 21 st century. Fort William, Scotland: RARARI, 2002.

10 Tucker J, Graham W, Hall, MH. Limited access to alternative models of care in UK maternity services: barriers to change. In: Davies HTO, Tavakoli $M$ Malek $M$, eds. Quality in health care: strategic issues in health care management. Aldershot: Ashgate Publishing, 2001:217-26.

11 Scottish Executive Health Department. National Framework for Maternity Services in Scotland. Edinburgh: Scottish Executive Health Department, 2001.

12 World Health Organisation. Nurses and midwives for health: WHO European strategy for nursing and midwifery education, Guidelines Section 2: Competency-based education and training. Copenhagen: World Health Organisation, 2001

13 NHS Scotland Information and Statistics Division (ISD). National statistics release: live births by mode of delivery and \% induced by hospital lyear ending 31 March 2001) (http://www.isdscotland.org/isd/files/ mat_bb_table5.xls). 
14 Bowling A. Research methods in health. 2nd edn. Buckingham: Open University Press, 2002

15 Bogdan RC, Biklen SK. Qualitative research for education. Boston: Allyn and Bacon, 1982.

16 Strauss AL, Corbin J. Basics of qualitative research. Newbury Park, CA: Sage, 1990.

17 Mays N, Pope C. Rigour and qualitative research. BMJ 1995;311:109-12.

18 Norusis MJ SPSS 7. 5 guide to data analysis. Chicago: Prentice Hall, 1997.

19 Department of Trade and Industry. EU Working Time Regulations: Working Time Directive-excluded sectots (junior doctors), http://www.dti.gov.uk/er/ work_time_regs/exsectors. htm\#junior.

20 Turnbull D, McGinley M, Holmes A, et al. The establishment of a midwifery development unit based at Glasgow Maternity Hospital (final report). Glasgow: Glasgow Royal Maternity Hospital, 1995.

21 Hogg M, Tucker J, Barnett C, et al. Evaluating the introduction of team midwifery in Ninewells Hospital (1996-1997): final report. Dundee: Dundee Teaching Hospitals NHS Trust, 1998:43-55.
22 Ericsson KA, Krampe RT, Tesch-Romer C. The role of deliberate practice in the acquisition of expert performance. Psychol Rev 1993;100:363-406.

23 Ramsay C, Grant AM, Wallace SA, et al. Assessment of the learning curve in health technologies - a systematic review. Int J Technol Assess Health Care 2000;16:1095-8.

24 Carr-Hill R, Place M, Posnett J. Access and utilisation of healthcare services. In: Fergusson B, Posnett J, Sheldon T, eds. Concentration and choice in health care. London: Royal Society of Medicine Press, 1997.

25 Tucker J, Stimpson P, Farmer J. Guidelines and management of mild hypertensive conditions in pregnancy in rural general practices in Scotland: issues of appropriateness and access. Qual Saf Health Care 2003; 12:286-90.

26 Cronin C, Cheang S, Hlynka D, et al. Videoconferencing can be used to assess neonatal resuscitation skills. Med Educ 2001:35:1013-23.

27 Murphy E, Dingwall R, Greatbatch D, et al. Qualitative research methods in health technology assessment: a review of the literature. Health Technol Assess 1998;2(16)

\section{Clinical Evidence-Call for contributors}

Clinical Evidence is a regularly updated evidence-based journal available worldwide both as a paper version and on the internet. Clinical Evidence needs to recruit a number of new contributors. Contributors are healthcare professionals or epidemiologists with experience in evidence-based medicine and the ability to write in a concise and structured way.

Areas for which we are currently seeking authors:

- Child health: nocturnal enuresis

- Eye disorders: bacterial conjunctivitis

- Male health: prostate cancer (metastatic)

- Women's health: pre-menstrual syndrome; pyelonephritis in non-pregnant women

However, we are always looking for others, so do not let this list discourage you.

Being a contributor involves:

- Selecting from a validated, screened search (performed by in-house Information Specialists) epidemiologically sound studies for inclusion.

- Documenting your decisions about which studies to include on an inclusion and exclusion form, which we keep on file.

- Writing the text to a highly structured template (about 1500-3000 words), using evidence from the final studies chosen, within 8-10 weeks of receiving the literature search.

- Working with Clinical Evidence editors to ensure that the final text meets epidemiological and style standards.

- Updating the text every six months using any new, sound evidence that becomes available. The Clinical Evidence in-house team will conduct the searches for contributors; your task is simply to filter out high quality studies and incorporate them in the existing text.

- To expand the topic to include a new question about once every 12-18 months.

If you would like to become a contributor for Clinical Evidence or require more information about what this involves please send your contact details and a copy of your CV, clearly stating the clinical area you are interested in, to Klara Brunnhuber (kbrunnhuber@ bmigroup.com).

\section{Call for peer reviewers}

Clinical Evidence also needs to recruit a number of new peer reviewers specifically with an interest in the clinical areas stated above, and also others related to general practice. Peer reviewers are healthcare professionals or epidemiologists with experience in evidence-based medicine. As a peer reviewer you would be asked for your views on the clinical relevance, validity, and accessibility of specific topics within the journal, and their usefulness to the intended audience (international generalists and healthcare professionals, possibly with limited statistical knowledge). Topics are usually 1500-3000 words in length and we would ask you to review between 2-5 topics per year. The peer review process takes place throughout the year, and our turnaround time for each review is ideally 10-14 days.

If you are interested in becoming a peer reviewer for Clinical Evidence, please complete the peer review questionnaire at www.clinicalevidence.com or contact Klara Brunnhuber (kbrunnhuber@bmigroup.com). 